updated feedback from receiving facilities and have basic life support providers preferably provide extrication and movement to an evacuation point while advanced life support providers provide secondary triage and transport with advanced treatment begun (preferably) enroute; 8) Log events for subsequent evaluation recognizing that media can be useful in chronicling events as well as for informing the public of hazards and any need for specialized assistance; 9) Provide post-incident care for rescuers, victims and incoming family/friends including immediate debriefings, protection from legal and media opportunists, as well as simple food, shelter and medical care; 10) Train and test all potential rescuers including the lay public and auxillary agencies.

\section{THE TRAINING OF UNDERGRADUATE MEDICAL STUDENTS IN DISASTER AND EMERGENCY MANAGEMENT}

\author{
Morgan Fahey, O.B.E., M.D.ChB., \\ F.R.N.Z.C.G.P., Christchurch, New Zealand
}

This paper will discuss the challenges to improve world wide the standards of undergraduate training in emergency and disaster medicine. Successful methods of teaching traffic medicine, mass casualty management and airport disaster preparedness will be presented, answering the questions who should be taught, who should teach and how should the subjects be taught. The paper will conclude that emergency and disaster medicine are neglected topics in many countries and the challenges remain to improve standards of teaching for the future.

\section{MAJOR AND MINOR TOXICOLOGICAL DISASTERS: ORGANIZATION OF PREVENTION AND TREATMENT}

Sergio I. Magalini, M.D., Rome, Italy

To reduce the potential risks in toxicological disasters the following steps will be discussed: 1) To prepare and keep an updated map of where toxic substances are produced or stored. 2) To collect documentation on the nature of the toxic substance used, the metabolites formed during their production or those developed following accidental events (fire, water, air, contact). 3) To preidentify generic and specific measures to prevent or reduce damage to person or the environment (flora and fauna) and the treatment of eventual lesions. 4) To authorize transport of toxic substances only when provided with the documentation indicated in point 2. 5) To establish a "direct line of communication" and continuous consultation between manufacturers and transporters and Poison Centers, which could act as coordinators both in the preventive and therapeutic phases from the site of accident to the hospital care.

\section{TRAINING IN DISASTER MEDICINE}

\section{Adriaan J.H. Korver, M.D., The Hague, The Netherlands}

A disaster is a situation where there is a discrepancy between the demand for medical aid and the supply of it, on the one hand, and where the aid given has to be in specific accordance with the disaster in order to be able to fight the disaster's consequences, on the other.

The medical care (mostly referred to as disaster aid) has to be such that the largest number of those victims whose life or health are in serious danger, are given the largest amount of help. Doctors will have to concentrate on providing curative and preventive care, while taking the disaster situation into account. Disaster is "mass" aid. This demands a different frame of thinking: individual care is not possible.

This paper details more specifically the theoretical and practical knowledge doctors need to have in order to be able to provide adequate relief in disaster situations.

\section{THE NAEMSP: A SOURCE OF A PHYSICIAN NETWORK FOR MAJOR INGIDENTS IN THE U.S.A.}

\author{
Paul E. Pepe, M.D., Raymond L. Fowler, M.D. \\ and Ronald Stewart, M.D., Houston, \\ Texas, U.S.A.
}

In recent conferences on disaster medicine in the United States, a recurrent debate has arisen regarding the role of physicians at the scene of a major incident. While most agree, in theory, that expert, knowledgable medical participation is desirable, it has been the experience of most civil authorities that 